CLINICAL STUDY

\title{
Hormone therapy protects from diabetes: the Kuopio osteoporosis risk factor and prevention study
}

\author{
Kati Pentti $^{1}$, Marjo T Tuppurainen ${ }^{1,3}$, Risto Honkanen ${ }^{3,6}$, Lorenzo Sandini $^{2,3}$, Heikki Kröger ${ }^{3,4}$, Esko Alhava ${ }^{5}$ \\ and Seppo Saarikoski ${ }^{1}$ \\ ${ }^{1}$ Department of Obstetrics and Gynecology, Kuopio University Hospital, FIN-70211 Kuopio, Finland, ${ }^{2}$ Department of Internal Medicine, \\ Kuopio University Hospital, Kuopio, Finland, ${ }^{3}$ Bone and Cartilage Research Unit, University of Kuopio, Kuopio, Finland, ${ }^{4}$ Department of Orthopaedics, \\ Traumatology and Handsurgery, Kuopio University Hospital, Kuopio, Finland, ${ }^{5}$ Department of Surgery, Institute of Clinical Medicine, Kuopio University \\ Hospital, Kuopio, Finland and ${ }^{6}$ Research Institute of Public Health, University of Kuopio, Kuopio, Finland
}

(Correspondence should be addressed to K Pentti; Email: kati.pentti@fimnet.fi)

\begin{abstract}
Objectives: The purpose of this population-based prospective cohort study was to examine the effect of hormone therapy (HT) on incidence of diabetes mellitus (DM).

Design and methods: Eight thousand four hundred and eighty-three DM-free post-menopausal women aged 52-62 from the population-based Kuopio osteoporosis risk factor and prevention study were followed for 5 years from 1994-1999. Information about the use of HT and health events was obtained from three repeated questionnaires in 1989, 1994, and 1999. DM morbidity before and during the follow-up was obtained from the Registry of Specially Refunded Drugs of the Finnish Social Insurance Institution. Kaplan-Meyer survival curves and Cox's proportional-hazards models were used to estimate the risk of incident DM in relation to the use of HT.

Results: During the follow-up, 40.8\% DM-free post-menopausal women had never used HT, 27.3\% women were HT past users and $31.9 \%$ women had used HT presently during the follow-up. During the follow-up, 162 incident DM cases were recorded. Compared with never users of HT, the adjusted hazard ratio of DM was 0.81 (95\% confidence interval (CI) $0.57-1.16$ ) for only past users, 0.53 (95\% CI $0.24-1.15)$ in part-time (during the follow-up $<2.5$ years) users and 0.31 (95\% CI 0.16-0.60) in continuous (during the follow-up 2.5-5.0 years) users of HT.

Conclusions: HT use decreases the incidence of DM in post-menopausal women.
\end{abstract}

European Journal of Endocrinology 160 979-983

\section{Introduction}

Diabetes mellitus (DM) is one of the most common chronic diseases in the world. Type $2 \mathrm{DM}$ is increasingly being recognized as a critical health problem especially in middle-aged and elderly people (1). Obesity and physical inactivity are established risk factors for type 2 DM and cardiovascular comorbidities (2). It is estimated that the number of diabetic people in the world will double from 171 million in 2000 to 366 million in 2030. Globally, the prevalence of DM is similar in men and women, but it is slightly higher in men under the age of 60 and in women at older ages (3).

Recent studies have suggested that post-menopausal hormone therapy (HT) is associated with lower incidence of DM. The Heart Estrogen Progestin Replacement Study (HERS) (4) and the Women's Health Initiative (WHI) trials $(5,6)$ were the first randomized controlled studies showing the positive effects of HT on DM. Primarily, HERS (4) and the WHI $(5,6)$ studied the effects of HT on cardiovascular disease (CVD) and there was no improvement of cardiovascular outcomes but, on the contrary, a significantly lower incidence of DM among HT users. Some (7) but not all $(8,9)$ observational studies have also noted a decreased incidence of DM among post-menopausal HT users.

The primary aim of this prospective 5-year study from the population-based study cohort was to examine the effects of HT on the incidence of DM in post-menopausal women.

\section{Materials and methods}

\section{Study population}

This study is a part of the Kuopio osteoporosis risk factor and prevention population-based prospective cohort study. The target population primarily consisted of the 14220 women resident in Kuopio Province and born in 1932-41 (aged 52-62 years in 1994) to whom a postal inquiry was sent in May 1989. The study population has 
been described in detail previously (10). In all, 13100 women $(92.8 \%)$ responded. The second follow-up inquiry was sent to women alive in May 1994. A total of 11798 women responded to both inquiries. Women whose HT use in May 1994 could not be clarified were excluded $(n=131)$. A woman was regarded as postmenopausal if $\geq 12$ months had elapsed since her last natural menstruation or if she had undergone bilateral oophorectomy before May 1994. A total of 839 premenopausal women and women whose menopause could not be defined due to hysterectomy $(n=1146)$ or to incomplete data $(n=328)$ were also excluded from the study. Women were considered to have previous DM if they self-reported DM, present use of insulin or oral glucose-lowering medications in 1989 or 1994 and women with that information about DM before the start of follow-up according to the Registry of Specially Refunded Drugs of the Finnish Social Insurance Institution (SII; total $n=282$ ). There were 9072 postmenopausal non-diabetic women in May 1994. In total 8483 (of 9072) post-menopausal women also responded to the third follow-up inquiry in May 1999 which formed the final study population of this study.

This study was approved by the local ethics committee in 1986, 1994, and 1997.

\section{Hormone therapy}

The lifetime use of HT in years before the baseline of this study was recorded in two postal enquiries in 1989 and 1994. The duration of HT use in months for each year of follow-up from 1994-1999 was recorded by postal enquiry in 1999. Inconsistent or missing HT information was clarified by telephone interview or by additional postal enquiry. HT use was defined as use of preparations having systemic estrogenic properties, and classified in four categories as follows: never, only in the past (before baseline 1994), part-time $(<2.5$ years of HT use during the follow-up) and continuous (2.5-5.0 years of HT use during the follow-up). The uniformity of HT use was examined and was found to be approximately uniform throughout the follow-up.

\section{Diabetes}

New cases of established DM during the follow-up $(n=162)$ were ascertained with the Registry of Specially Refunded Drugs of the SII. According to the National Sickness Insurance, the SII granted 100\% reimbursement for drug costs in defined chronic illnesses necessitating continuous medication, like DM.

According to the National Sickness Insurance, the criteria for reimbursement of medicines in DM (ICD-9 codes 250.0-250.9 and ICD-10 codes E10-E14, E89.1) are as below:

Examinations and diagnosis of type 1 diabetes (DM1) and type 2 diabetes (DM2) have to be made in the specialized health care unit or by a specialist physician. Owing to high prevalence of DM2, right to reimbursement can be based also upon an opinion from any physician.

I. Patient has the right to reimbursement for DM2 medication when the patient has typical symptoms of DM (polyuria, polydipsia, and glucosuria) and fasting glucose in capillary or vein blood is at least $7.0 \mathrm{mmol} / \mathrm{l}$ or in plasma blood at least $8.0 \mathrm{mmol} / \mathrm{l}$. If the symptoms of DM are missing, DM diagnosis has to be confirmed by repeated testing.

II. Patient has the right to reimbursement for DM2 medication when the patient has used DM medication for at least 6 months and the positive effects of medication have been described. An overweight DM2 patient must undergo at least 6 months of dietary treatment before medical treatment. The medical certificate concerning DM2 must include information about the duration of diet use and its effects on weight. Furthermore, the symptoms, findings, and blood and urine glucose status and possible albuminuria, especially before medical treatment, may be described. When DM diagnosis has been made, a medical doctor will write the statement to the SII, which will then give the patient the right to reimbursement for DM (The Finnish Social Insurance Institution (Kela); http://www.kela.fi/in/ internet/suomi.nsf/NET/040304095807UK?open Document). In the present study, the date of a physician's statement for DM was used as the endpoint of DM follow-up. In all, 162 post-menopausal women had new incident DM during the follow-up.

\section{Other variables}

The inquiries included questions about gynecological history (parity, last menstruation, and menopausal symptoms) and surgery, height, weight, smoking, and chronic health disorders diagnosed by physician (with $>100$ different items). Present medication prescribed by a doctor was also asked in both inquiries: as well as the names of medications (including duration of use) and diseases that they were taking medications for. SII registry was used together with the inquiries in 1989 and 1994 to determinate the women's baseline status concerning the occurrence of hypertension and hypercholesterolaemia. Body mass index (BMI) was calculated as the ratio of weight in kilograms to height in square meters $\left(\mathrm{kg} / \mathrm{m}^{2}\right)$.

\section{Statistical analysis}

The statistical analyses were performed with the SPSS (INC 14.0) program. The differences in baseline characteristics between HT users (during the follow-up) and never users were tested by using ANOVA to compare the means of continuous variables and the $\chi^{2}$-test to 
Table 1 Baseline characteristics (in 1994) of the 8483 non-diabetic post-menopausal women according to the hormone therapy (HT) use.

\begin{tabular}{|c|c|c|c|c|c|}
\hline \multirow[b]{2}{*}{ Characteristic } & \multicolumn{5}{|c|}{ Use of HT } \\
\hline & Never & Past & Current $^{a}$ & Total & $P$ \\
\hline$n(\%)$ & $3463(40.8 \%)$ & $2314(27.3 \%)$ & 2706 (31.9\%) & 8483 & \\
\hline Age (mean, (s.D.)) & $58.1(2.8)$ & $57.7(2.8)^{\dagger}$ & $56.6(2.7)^{\dagger}$ & $57.6(2.8)$ & $<0.001$ \\
\hline BMI $\left(\mathrm{kg} / \mathrm{m}^{2}\right.$, mean (S.D.)) & $27.5(4.7)$ & $27.4(4.3)$ & $25.9(3.6)^{\dagger}$ & $27.0(4.3)$ & $<0.001$ \\
\hline Parity (mean, (s.D.)) & $2.6(1.7)$ & $2.5(1.6)$ & $2.3(1.4)^{\dagger}$ & $2.5(1.6)$ & $<0.001$ \\
\hline Smoking (\%) & 18.5 & 19.5 & 19.1 & 18.9 & 0.608 \\
\hline Chronic hypercholesterolemia (\%) & 16.6 & 18.2 & 15.0 & 16.5 & 0.010 \\
\hline Chronic hypertension (\%) & 24.9 & $28.2^{*}$ & $22.1^{*}$ & 24.9 & $<0.001$ \\
\hline Hysterectomy (\%) & 6.5 & $11.6^{*}$ & $20.0^{*}$ & 12.2 & $<0.001$ \\
\hline
\end{tabular}

Comparison of each HT group with non-users by $1994,{ }^{*} P<0.05, \chi^{2}$-test, ${ }^{\dagger} P<0.05$, ANOVA.

${ }^{a}$ During follow-up.

compare categorical variable distributions. $P$ values of $<0.05$ were considered significant. Kaplan-Meier survival curves with the log rank test were used to examine the effect of HT use on the incidence of DM. KaplanMeier survival curves were also used for evaluation of the applicability of life table models (which assume constant incidence of endpoint events) on our data. Cox's proportional-hazard models were used to study the association of HT use with DM incidence after adjustment for covariates. The covariates used age, parity, BMI, hypertension (no, yes), hypercholesterolaemia (no, yes), status of hysterectomy (no, yes), and smoking history (never, ever). Possible interactive effects of HT use and these covariates on the risk of DM were examined using correlation matrices from Cox's models. Follow-up times were calculated as the time from the 1st of June 1994 to 31st of May 1999 or date of reimbursement decision about DM from SII, whichever came first. $P$ values of $<0.05$ were considered significant.

\section{Results}

Past use of HT was reported by $27.3 \%$ and current HT use during the follow-up by $31.9 \%$ of the 8483 non-diabetic post-menopausal women during the 5 years follow-up. Mean duration of current HT use during the follow-up was 3.75 years. HT use during follow-up was quite evenly distributed for the 5 years of follow-up. The rest (40.8\%) of women had neither used HT nor started it during the follow-up. The average follow-up time was 4.96 years (range 0.04-5.00). There were some marked differences in baseline characteristics between HT users and nonusers (Table 1). Women who used HT during the follow-up HT were slightly younger, had a lower BMI and had fewer children than non-users. HT users during the follow-up reported slightly less hypertension than never users. Women who used HT only in the past more often had hypertension than never users. HT users had undergone more hysterectomies than never users (Table 1).

During the follow-up, 162 new DM events occurred $(n=8483)$. The incidence of the DM remained constant throughout the follow-up. Overall, 90 DM incidents were found in HT never users, $51 \mathrm{DM}$ incidents in only past HT users, 8 DM incidents in part-time $(<2.5$ years $)$ HT users, and 13 DM incidents in continuous (2.5-5.0 years) HT users in the whole cohort (Table 2 and Fig. 1). The DM incidence was 3.85 per 1000 person-years in the whole cohort, 5.26 per 1000 person-years, in HT never users, 4.45 per 1000 person-years in only in the past users, 2.34 per 1000 person-years in part-time $(<2.5$ years) HT users and 1.29 per 1000 person-years in continuous (2.5-5.0 years) HT users respectively.

The use of HT was associated with a decreased risk of DM in the post-menopausal women. In the multivariate Cox regression analysis, the risk of DM as hazard ratio was 0.81 (95\% CI $0.57-1.16)$ in only past HT users, 0.53 (95\% CI 0.24-1.15) in women who used HT part-time $(<2.5$ years $)$ during the follow-up and 0.31 (95\% CI 0.16-0.60) in women who used HT continuous (2.5-5.0 years) during the follow-up compared with HT never users (Table 2). None of the covariates interacted with HT use.

\section{Discussion}

In the present population-based 5-year prospective cohort study on post-menopausal women, HT use significantly decreased the risk of developing DM. The risk decrease was accentuated (69\%) in women who used HT more than half of the follow-up time.

Table 2 The relative risk of incident diabetes (DM) as hazard ratios with $95 \%$ confidence interval $(\mathrm{Cl})$ in relation to use of hormone therapy $(\mathrm{HT})$ in post-menopausal women during the 5 -year follow-up.

\begin{tabular}{lccc}
\hline & \multicolumn{3}{c}{$\mathrm{DM}(n=162)$} \\
\cline { 2 - 4 } Use of HT & $\mathrm{DM}(n)$ & Age-adjusted & \multicolumn{1}{c}{$\begin{array}{c}\text { Multivariate } \\
(95 \% \mathrm{Cl})\end{array}$} \\
\hline Never & 90 & 1.0 & 1.0 \\
Past & 51 & $0.86(0.61-1.21)$ & $0.81(0.57-1.16)$ \\
$\begin{array}{c}\text { Part-time } \\
(<2.5 \text { years })\end{array}$ & 8 & $0.46(0.22-0.94)$ & $0.53(0.24-1.15)$ \\
$\begin{array}{c}\text { Continuous } \\
(\geq 2.5 \text { years })\end{array}$ & 13 & $0.26(0.15-0.47)$ & $0.31(0.16-0.60)$ \\
\end{tabular}

Multivariate covariates: age, BMI $\left(\mathrm{kg} / \mathrm{m}^{2}\right)$, parity, hypertension $(\mathrm{n} / \mathrm{y})$, hypercholesterolemia $(n / y)$, hysterectomy $(n / y)$ and smoking (never, ever). 


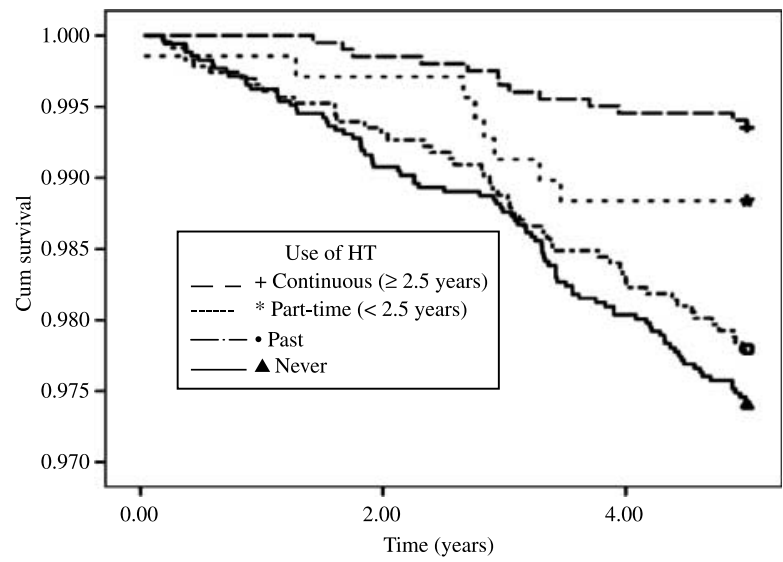

Figure 1 Remaining free of diabetes according to the HT use (Kaplan-Meier survival curves). Log rank $P<0.001$.

The strengths of this study include its populationbased nature, detailed information about HT use and careful diagnosis of incident IDDM based on the registry of specially refunded drugs of the SII. The registries in Finland have proven to be reliable (11). A limitation of our study was that baseline characteristics of current HT users had fewer risk factors than HT non-users. However, adjusting for those characteristics did not affect the results. In addition, no interactions between HT use and these factors were found. Our study did not distinguish between unopposed estrogen and combined therapy or between oral and transdermal application.

Several observational studies and RCTs have examined the role of HT use in the prevention of DM but none of those studies has found as strong a preventive effect as this study (4-7). Manson et al. (7) reported a 20\% lower incidence of DM in women using HT compared with women who did not use it in the Nurse's Health Study. In a randomized controlled trial, the HERS study (4), the corresponding decrement was 35\%. Lastly, the WHI trial reported $11-17 \%$ lowered risk of DM in HT users compared with non-users $(5,6)$. On the other hand, the Strong Heart Study (8) reported that the risk of type 2 DM increased by 10\% per year of present estrogen use, while Gabal et al. (9) did not find a statistically significant change in DM risk related to HT use.

Unlike these studies, in our present study in postmenopausal women, DM risk reduction related to current HT use during the follow-up was remarkable (62\% for all current HT users during the follow-up) compared with never users. The great majority of the women, who used HT during follow-up of our study had started HT before baseline. This long-term HT exposure may partly explain the results of our study. Women who have used HT only in the past and may have stopped the use of HT before the follow-up may have lost part of its benefit, whereas women who have started HT use only a short time ago may not have yet reached the full benefit of it. Finnish women with an intact uterus mainly use oestradiol $\left(\mathrm{OE}_{2}\right)$ combined with norethisterone acetate or levonorgesterel. Finnish women who have undergone hysterectomy use mainly $\mathrm{OE}_{2}$ only.

During menopause, women gain body fat in the abdominal region, and insulin sensitivity decreases $(12,13)$. These changes, along with dyslipidemia and hypertension, are consistent with the metabolic syndrome and predict DM2 (14) and coronary heart disease (15) in post-menopausal women. HT can have favorable effects on body fat distribution and could, therefore, act to reduce DM risk via this mechanism (16).

Several studies indicate that estrogen therapy may attenuate the accumulation of central fat in postmenopausal women (17-20). In the PEPI trial (21), less weight gain or increase in waist and hip circumferences were registered in women who received $\mathrm{E}+\mathrm{P}$ therapy compared with placebo. Similarly, in the Danish osteoporosis prevention study (22), HT use seemed to have a weight-reducing effect.

There are several mechanisms other than effects on adiposity tissue and body fat distribution by which HT may be protective against DM. In a prospective study of older women not using HT, endogenous levels of bioavailable $\mathrm{OE}_{2}$ and testosterone were positively associated with levels of fasting glucose, insulin, and estimated insulin resistance, whereas only bioavailable testosterone predicted incident DM (23). Positive associations of bioavailable $\mathrm{OE}_{2}$ and testosterone with insulin resistance have also been observed in a cross-sectional study of untreated post-menopausal women (24). Low levels of sex hormone binding globulin are related negatively with obesity, insulin resistance, and incidence of DM in postmenopausal women (25-27). Hyperandrogenicity in women is closely associated with insulin resistance and risk factors for CVD and type $2 \mathrm{DM}$.

It has been hypothesized that estrogen may also have a direct effect on secretion of insulin by the pancreas. For example, estrogen receptors are present in pancreatic $\beta$-cells (28), and estrogen increases the release of insulin in $\beta$-cell culture models (29).

In conclusion, the present prospective cohort study indicates that HT use reduces the risk of DM in postmenopausal women. Further information on the role of HT, according to the route of administration and dose in modifying the risk of DM is needed.

\section{Declaration of interest}

None declared.

\section{Funding}

The authors would like to thank Kuopio University Hospital (EVOgrant), the Finnish Menopause Society (grant), the Academy of Finland (grant), National Statistics Finland, and the Finnish Social Insurance Institution for support of this work. 


\section{References}

1 Mokdad AH, Ford ES, Bowman BA, Dietz WH, Vinicor F, Bales VS \& Marks JS. Prevalence of obesity, diabetes, and obesity-related health risk factors, 2001. Journal of the American Medical Association 2003 289 76-79.

2 Sullivan PW, Morrato EH, Ghushchyan V, Wyatt HR \& Hill JO. Obesity, inactivity, and the prevalence of diabetes and diabetesrelated cardiovascular comorbidities in the US, 2000-2002. Diabetes Care 200528 1599-1603.

3 Wild S, Roglic G, Green A, Sicree R \& King H. Global prevalence of diabetes: estimates for the year 2000 and projections for 2030. Diabetes Care 200427 1047-1053.

4 Kanaya AM, Herrington D, Vittinghoff E, Lin F, Grady D, Bittner V, Cauley JA \& Barrett-Connor E, Heart and Estrogen/Progestin Replacement Study. Glycemic effects of postmenopausal hormone therapy: the heart and estrogen/progestin replacement study. A randomized, double-blind, placebo-controlled trial. Annals of Internal Medicine 2003138 1-9.

5 Margolis KL, Bonds DE, Rodabough RJ, Tinker L, Phillips LS, Allen C, Bassford T, Burke G, Torrens J \& Howard BV, Women's Health Initiative Investigators. Effect of oestrogen plus progestin on the incidence of diabetes in postmenopausal women: results from the Women's Health Initiative Hormone Trial. Diabetologia 200447 1175-1187.

6 Bonds DE, Lasser N, Qi L, Brzyski R, Caan B, Heiss G, Limacher MC, Liu JH, Mason E, Oberman A, O’Sullivan MJ, Phillips LS, Prineas RJ \& Tinker L. The effect of conjugated equine oestrogen on diabetes incidence: the Women's Health Initiative randomised trial. Diabetologia $2006 \mathbf{4 9} 459-468$.

7 Manson JE, Rimm EB, Colditz GA, Willett WC, Nathan DM, Arky RA, Rosner B, Hennekens CH, Speizer FE \& Stampfer MJ. A prospective study of postmenopausal estrogen therapy and subsequent incidence of non-insulin-dependent diabetes mellitus. Annals of Epidemiology 19922 665-673.

8 Zhang Y, Howard BV, Cowan LD, Yeh J, Schaefer CF, Wild RA, Wang W \& Lee ET. The effect of estrogen use on levels of glucose and insulin and the risk of type 2 diabetes in american Indian postmenopausal women: the strong heart study. Diabetes Care 200225 500-504.

9 Gabal LL, Goodman-Gruen D \& Barrett-Connor E. The effect of postmenopausal estrogen therapy on the risk of non-insulindependent diabetes mellitus. American Journal of Public Health 199787 443-445.

10 Pentti K, Honkanen R, Tuppurainen MT, Sandini L, Kroger H \& Saarikoski S. Hormone replacement therapy and mortality in 52- to 70-year-old women: the Kuopio osteoporosis risk factor and prevention study. European Journal of Endocrinology $2006 \mathbf{1 5 4}$ 101-107.

11 Suoyrjo H, Hinkka K, Kivimaki M, Klaukka T, Pentti J \& Vahtera J. Allocation of rehabilitation measures provided by the Social Insurance Institution in Finland: a register linkage study. Journal of Rehabilitation Medicine: Official Journal of the UEMS European Board of Physical and Rehabilitation Medicine 200739 198-204.

12 Toth MJ, Tchernof A, Sites CK \& Poehlman ET. Effect of menopausal status on body composition and abdominal fat distribution. International Journal of Obesity and Related Metabolic Disorders 2000 $24226-231$.

13 Wu SI, Chou P \& Tsai ST. The impact of years since menopause on the development of impaired glucose tolerance. Journal of Clinica Epidemiology 200154 117-120.

14 Lorenzo C, Okoloise M, Williams K, Stern MP, Haffner SM \& San Antonio Heart Study. The metabolic syndrome as predictor of type 2 diabetes: the San Antonio heart study. Diabetes Care 200326 3153-3159.

15 Rewers M, Zaccaro D, D’Agostino R, Haffner S, Saad MF, Selby JV. Bergman R, Savage P \& Insulin Resistance Atherosclerosis Study
Investigators. Insulin sensitivity, insulinemia, and coronary artery disease: the Insulin Resistance Atherosclerosis Study. Diabetes Care 200427 781-787.

16 Godsland IF. Oestrogens and insulin secretion. Diabetologia 200548 2213-2220.

17 Gambacciani M, Ciaponi M, Cappagli B, De Simone L, Orlandi R \& Genazzani AR. Prospective evaluation of body weight and body fat distribution in early postmenopausal women with and without hormonal replacement therapy. Maturitas 200139 125-132.

18 Sorensen MB, Rosenfalck AM, Hojgaard L \& Ottesen B. Obesity and sarcopenia after menopause are reversed by sex hormone replacement therapy. Obesity Research 2001 9 622-626.

19 Gambacciani M, Ciaponi M, Cappagli B, Piaggesi L, De Simone L, Orlandi R \& Genazzani AR. Body weight, body fat distribution, and hormonal replacement therapy in early postmenopausal women. Journal of Clinical Endocrinology and Metabolism 199782 414-417.

20 Davis SR, Walker KZ \& Strauss BJ. Effects of estradiol with and without testosterone on body composition and relationships with lipids in postmenopausal women. Menopause 20007 395-401.

21 Espeland MA, Stefanick ML, Kritz-Silverstein D, Fineberg SE, Waclawiw MA, James MK \& Greendale GA. Effect of postmenopausal hormone therapy on body weight and waist and hip girths. Postmenopausal Estrogen-Progestin Interventions Study Investigators. Journal of Clinical Endocrinology and Metabolism $1997 \mathbf{8 2}$ 1549-1556

22 Jensen LB, Vestergaard P, Hermann AP, Gram J, Eiken P, Abrahamsen B, Brot C, Kolthoff N, Sorensen OH, Beck-Nielsen H, Nielsen SP, Charles P \& Mosekilde L. Hormone replacement therapy dissociates fat mass and bone mass, and tends to reduce weight gain in early postmenopausal women: a randomized controlled, 5-year clinical trial of the Danish osteoporosis prevention study. Journal of Bone and Mineral Research 200318 333-342.

23 Oh JY, Barrett-Connor E, Wedick NM, Wingard DL \& Rancho Bernardo Study. Endogenous sex hormones and the development of type 2 diabetes in older men and women: the Rancho Bernardo study. Diabetes Care 200225 55-60.

24 Kalish GM, Barrett-Connor E, Laughlin GA, Gulanski BI \& Postmenopausal Estrogen/Progestin Intervention Trial. Association of endogenous sex hormones and insulin resistance among postmenopausal women: results from the Postmenopausal Estrogen/Progestin Intervention Trial. Journal of Clinical Endocrinology and Metabolism $2003 \mathbf{8 8} 1646-1652$.

25 Haffner SM, Dunn JF \& Katz MS. Relationship of sex hormonebinding globulin to lipid, lipoprotein, glucose, and insulin concentrations in postmenopausal women. Metabolism: Clinical and Experimental $1992 \mathbf{4 1} 278-284$.

26 Lindstedt G, Lundberg PA, Lapidus L, Lundgren H, Bengtsson C \& Bjorntorp P. Low sex-hormone-binding globulin concentration as independent risk factor for development of NIDDM. 12-yr follow-up of population study of women in Gothenburg, Sweden. Diabetes 199140 123-128.

27 Haffner SM, Valdez RA, Morales PA, Hazuda HP \& Stern MP. Decreased sex hormone-binding globulin predicts noninsulindependent diabetes mellitus in women but not in men. Journal of Clinical Endocrinology and Metabolism 1993 77 56-60.

28 Sutter-Dub MT. Rapid non-genomic and genomic responses to progestogens, estrogens, and glucocorticoids in the endocrine pancreatic B cell, the adipocyte and other cell types. Steroids 2002 67 77-93.

29 Nadal A, Ropero AB, Fuentes E, Soria B \& Ripoll C. Estrogen and xenoestrogen actions on endocrine pancreas: from ion channel modulation to activation of nuclear function. Steroids $2004 \mathbf{6 9}$ 531-536.

Received 18 March 2009

Accepted 23 March 2009 